\title{
LUTA PELA TERRA E TERRITÓRIO: MULHERES CAMPONESAS E OS DESAFIOS NA CONSTRUÇÃO DO ASSENTAMENTO OZIEL ALVES, PORTO FRANCO, MARANHÃO
}

\section{Alessandra da Conceição Morais (D)1 Rejane Cleide Medeiros de Almeida(D)2}

Resumo: O presente trabalho aborda os desafios das mulheres camponesas na luta pela terra e pelo território no município de Porto Franco, no Maranhão, buscando analisar como ocorreu a participação das mulheres nessa luta. A metodologia utilizada consistiu na abordagem qualitativa por meio de pesquisa de campo e entrevistas semiestruturadas, realizadas durante o período de 2018 a 2020 para o trabalho de conclusão de curso (TCC) da autora 1. Os resultados obtidos apontaram para a participação das mulheres nos núcleos de base (NBs) que fazem parte da organicidade do Movimento dos Trabalhadores Rurais SemTerra (MST), e nas assembleias que tratam de temas e demandas das ações e estratégias da luta pelo assentamento no período do acampamento. Também foi observada a atuação das mulheres na associação do assentamento, nos cuidados com as crianças e suas famílias, sobretudo na produção de hortas e ervas medicinais, nos quintais produtivos, depois de assentadas. Após alguns anos, o assentamento Oziel Alves produziu territorialidades e, atualmente, compõe o processo de territorialização do MST-MA.

Palavras-chave: Mulheres camponesas. MST. Território.

\section{STRUGGLE FOR LAND AND TERRITORY: PEASANT WOMEN AND CHALLENGES IN THE CONSTRUCTION OF THE OZIEL ALVES SETTLEMENT, PORTO FRANCO (MA)}

Abstract: This work will address the challenges of peasant women in the struggle for land and territory in the municipality of Porto Franco, Maranhão. The research sought to analyze how the participation of women in this struggle occurred. The methodology used a qualitative approach, with field research and semi-structured interviews. The same occurred in the period 2018 to 2020 for the completion of the course completion work of the author 1 . The results obtained in the research pointed to the participation of women in the base nuclei (NBs), which are part of the organicity of the workers' movement Without Land (MST), also pointed to the participation in the assemblies that dealt with themes and demands of actions and strategies of the struggle for the settlement during the camp period, as well as the role of women in the settlement association, in caring for the settlement. the children and their families, especially in the production of vegetable gardens and medicinal herbs in the productive

\footnotetext{
${ }^{1}$ Mestranda em Estudos de Cultura e Território na Universidade Federal do Tocantins (UFT). Email: sandramorais0695@gmail.com.

${ }^{2}$ Doutora em Sociologia pela Universidade Federal de Goiás (UFG). Professora do curso de Educação do Campo: Artes e Música, e do Programa de estudos em Cultura e Território (PPGCULT), da Universidade Federal do Norte do Tocantins (UFNT). E-mail: rejmedeiros@uft.edu.br.
} 
backyards, after they are settled. After a few years, the Oziel Alves settlement produced territorialities and is part of the territorialization process of the MSTMA.

Keywords: Peasant Women; MST; Territory.

\section{Introdução}

O debate sobre o tema "Luta pela terra e território: mulheres camponesas e desafios na construção do Assentamento Oziel Alves, Porto Franco (MA)" tem como objetivo analisar a participação das mulheres nessa luta. O texto é resultado da pesquisa desenvolvida para o trabalho de conclusão de curso (TCC) na graduação em Ciências Sociais. A questão que norteou a pesquisa constituiu-se nos desafios enfrentados pelas mulheres para a conquista do assentamento. Sobre assentamentos, Almeida (2017, p. 84) ressalta que "[...] constituem-se em uma das políticas de reforma agrária e representam um modelo de reforma agrária no Brasil. São, também, conquistas da luta dos movimentos sociais, de pressões e enfrentamentos com o latifúndio." A autora chama a atenção, ainda, para o fato de que:

No Brasil, o termo assentamento rural está ligado ao controle e à demarcação de novos espaços criados para atender à pressão dos trabalhadores rurais. No que tange às ações do governo, o termo referese à colonização e regularização fundiária e a criação e integração de novas propriedades rurais ao processo produtivo baseado na desapropriação de terras ociosas ou, também, na aquisição de imóveis rurais e crédito fundiário (ALMEIDA, 2017, p. 84).

Nesse sentido, o assentamento Oziel Alves foi uma luta da organização do Movimento dos Trabalhadores Rurais Sem-Terra (MST), que mobilizou e organizou as/os trabalhadoras/es sem-terra no Maranhão.

No que diz respeito a luta por terra e produções sociais, as mulheres camponesas organizam espaços de vida e de trabalho, reafirmando múltiplas identidades que foram construídas por meio de experiências de vida, convivência, resistência e luta por um projeto de vida. No assentamento Oziel, juntas lutaram pela terra e, posteriormente à conquista, pela organização do território.

Para este estudo, definir o conceito de "território" faz-se necessário para compreender os diferentes sentidos dos processos históricos e das formas de organização social, política, cultural e econômica empreendidos por uma sociedade. Cada sociedade produz seu território e sua territorialidade; produz seu modo de viver conforme normas, regras, crenças, valores, ritos e mitos específicos, de acordo com as próprias atividades cotidianas. Como destaca Saquet (2007), o território é a síntese das ações entre os processos históricos e relacionais produzidos a partir das relações entre os diferentes grupos sociais.

No território que se forma, propõe-se outra organização do espaço e da organização social. Assim, a partir da posse da terra, as famílias adquirem novas orientações de atividades diárias, trabalho e relações internas e externas. 
Almeida destaca que:

[...] o papel que vêm desempenhando ao longo do processo histórico na luta pela terra o MST e as relações de gênero constituem-se em avanços, mas, contraditoriamente, em recuos, haja vista que as mulheres em luta buscam também sua inserção nas práticas sociais para a conquista da igualdade de gênero, seja nos espaços da luta social, do trabalho, quanto da política e isto não se configura facilmente (ALMEIDA, 2017, p. 198).

A autora afirma que as mulheres camponesas buscam organizar-se lutando por participação em questões relacionadas a política, trabalho, educação, saúde e terra. Hoje, a luta do coletivo de mulheres do MST apresenta, sobretudo, elementos contra o racismo estrutural e o patriarcado. Nesses espaços, são potencializadas as possibilidades de visibilização da necessidade do reconhecimento da força política e produtiva da mulher.

No que se refere à formação política, dirige-se à compreensão das condições de vida e à aplicação das leis - como o Estatuto do Trabalhador Rural e o Estatuto da Terra - e desencadeia a organização de grupos de trabalhadores rurais para comporem chapas sindicais e participarem das suas eleições. As mulheres camponesas tomam assento nesses espaços e, desde a década de 1980, ingressam em partidos políticos, participam das atividades das centrais sindicais e reivindicam lugares de participação na luta política.

O protagonismo das mulheres na luta política pela terra e no processo de assentar famílias no campo ocorre com a territorialização e com sua representação no território onde se situa o assentamento. O assentamento Oziel é formado por uma área pouco extensa para os moradores, mas já possui uma estrutura com casas, roças, unidade escolar, igrejas e comércios. São nesses espaços que as mulheres camponesas se situam e desempenham seu papel atuante nas lutas pela terra. O assentamento -localizado na BR 334, próximo ao município de Porto Franco, MA - foi conquistado na luta pela terra em 2010; nele, foram assentadas 22 famílias.

Por meio das entrevistas, buscamos compreender a forma como ocorre o protagonismo das mulheres camponesas nesse processo de resistência e luta pela terra como um direito social. Procuramos entender a singularidade de cada história, não desconsiderando as aproximações existentes nas suas particularidades, tendo em vista que suas origens apresentam, dentre outras semelhanças, a vinculação ao mundo rural. A intenção é identificar e analisar, por meio das entrevistas semiestruturadas, as suas participações na construção e organização do assentamento Oziel Alves. A fim de atingir o objetivo proposto, buscamos entender, também, os espaços sociais em que as mulheres vivem e suas trajetórias de luta no processo da construção do assentamento e em outros espaços por elas ocupados (ALMEIDA, 2017).

A metodologia de estudo compreendeu uma abordagem qualitativa, com história de vida e entrevistas semiestruturadas. A pesquisa ocorreu no período de 2018 a 2020, e contou, também, com observações no assentamento. Foram realizadas seis entrevistas com as mulheres que estão desde o início da formação do acampamento. Os resultados obtidos apontaram para a participação das mulheres nos núcleos de base (NBs) que fazem parte da 
organicidade do MST, para sua participação nas assembleias que tratam de temas e demandas relacionadas às ações e estratégias da luta pelo assentamento no período do acampamento, e para sua atuação na associação do assentamento, nos cuidados com suas crianças e famílias e, sobretudo, na produção de hortas e ervas medicinais, nos quintais produtivos, após estarem assentadas. Passados alguns anos, 0 assentamento Oziel Alves produziu territorialidades e, hoje, compõe o processo de territorialização do MST-MA.

O artigo está dividido em duas seções além das considerações e das referências. A primeira seção aborda os conflitos enfrentados pelos camponeses, além da infraestrutura e da organização política do assentamento. A segunda seção relata a conquista do assentamento, quando foi possível compreender o processo de participação das mulheres camponesas e seu protagonismo político. Nesse processo, são abordados temas como a trajetória de luta dos assentados e os aprendizados adquiridos nos acampamentos até a conquista da terra, destacando os espaços ocupados pelas mulheres camponesas e o seu envolvimento com a luta pela terra.

\section{Assentamento Oziel Alves: lutas e conquistas}

Com base nas análises e leituras realizadas sobre o tema, observou-se que o MST é um movimento que mobiliza muitas famílias na luta pela terra, e que as mulheres estão presentes nessa luta. No movimento, a questão de gênero é entendida com a participação de homens e mulheres, buscando desvelar o papel social da mulher e contribuindo para a formação política dos sujeitos em luta.

O MST, que se destaca como um importante movimento social, no Brasil, tem como um de seus objetivos principais a reforma agrária brasileira. "A organização do MST enquanto movimento social começou nos anos de 1980 e desde, então conseguiu ampliar sua presença, estando presente em 24 Estados da Federação." (MST, 2016, s/p).

Os objetivos do MST para além da reforma agrária estão no bojo das discussões sobre as transformações sociais importantes ao Brasil, principalmente aquelas tocantes à inclusão social, sendo que, se por um lado existiram avanços e conquistas nesta luta há muito ainda por se fazer com relação à reforma agrária, assentamentos e infraestrutura disponível as famílias já assentadas (MST, 2016, s/p).

Quando um acampamento se constitui em assentamento, isso não quer dizer que a luta acabou; ainda existem desafios significativos a serem vencidos, como a conquista de uma organização efetiva interna e de uma estrutura de saneamento básico condizente com a qualidade de vida esperada, com água encanada, rede de energia, escolas, estradas que garantam boas condições de locomoção, transportes escolares etc. A Figura 1 representa a localização do assentamento na BR 334, a 6km da estrada de São João do Paraíso (MA). 


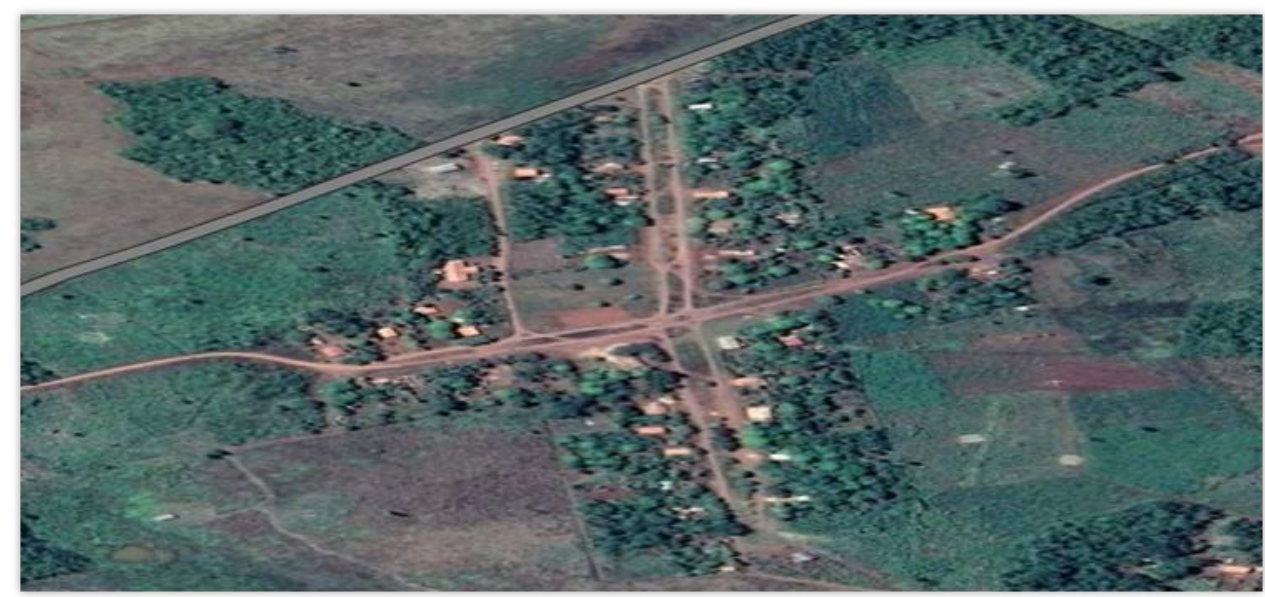

Figura 1: Assentamento Oziel Alves.

Fonte: https://www.google.com/maps, 2019.

Em 2010, foi decretado por lei que os acampados passariam a ser assentados no Assentamento Oziel Alves, nome determinado em homenagem ao jovem assassinado na "Curva do S", em Carajás, Pará. Segundo a interlocutora Nilza Carvalho:

Foi escolhido esse nome por causa de um rapaz que era militante do MST. Representava aquelas pessoas que mataram no confronto, no Pará, não tem aquele assentamento que botaram o nome de um padre que mataram no confronto? (Entrevistada, NILZA CARVALHO, 2019).

A fala da interlocutora aponta para o fato de que o MST homenageia as/os suas/seus trabalhadoras/es que tombam na luta pela terra. Segundo Nilza, ao ocupar um território, geralmente esse recebe o nome de um militante que morreu durante a luta. Nessa dimensão, Tuan (1983, p. 17) destaca que o "[...] sentimento revela a maneira pela qual o 'eu' é afetado." Essa é uma das ações em que as assentadas homenageiam as/os companheiras/os que morreram lutando para conquistar a terra; uma morada para produções da vida.

Para a conquista da terra, foram muitos os desafios, que vão desde a época de acampamento até o assentamento das famílias. Segundo as pesquisas realizadas no período de 2018 a 2020, durante a conquista da terra (e após a terra conquistada) as mulheres camponesas tiveram que enfrentar diversos problemas relacionados a fazendeiros, polícia e outras questões, vivendo um processo de desterritorialização e territorialização, por vários anos, uma vez que sofreram diversos despejos judiciais. Desde 2010, quando foram assentadas, mantiveram suas culturas e suas histórias, vivendo em tempos de medo e angústia.

Por cultura, compreendemos uma expressão de reafirmação presente nas territorialidades. Tratar sobre cultura é considerar regras de comportamentos que implicam significados para os que as vivenciam. Assim, "[...] um ser humano sem cultura seria apenas uma monstruosidade sem mente." (GERTZ, 2008, p. 50). A mente humana, portanto, é dependente de recursos naturais, e a cultura não é apenas um complemento, mas um ingrediente para o cérebro. 
Sobre territorialidades, Raffestin (1993) afirma que são conjuntos de relações mediatizadas que derivam do sistema sociedade-espaço-tempo e se associam à organização do espaço. Para o autor:

É essencial compreender bem que o espaço é anterior ao território. O território se forma a partir do espaço, é o resultado de uma ação conduzida por um ator sintagmático (ator que realiza um programa) em qualquer nível. Ao se apropriar de um espaço, concreta ou abstratamente [...] o ator "territorializa" o espaço (RAFFESTIN, 1993, p. 143).

De acordo com o autor, pode ser entendido como território nacional o espaço físico onde se localiza uma nação, onde se delimita uma ordem jurídica e política, ou seja, uma produção a partir do espaço onde ocorrem relações de poder exercidas pelos homens (RAFFESTIN, 1993). Como já ressaltado, em 2010 foi decretado que os acampados passariam à condição de assentados, iniciando um processo de territorialização e sociabilidade.

O assentamento surgiu a partir do acampamento em 4 de junho de 2004. O MST organizou uma reunião e decidiu realizar sua primeira ocupação na Fazenda Santa Maria. Segundo Francisca Silva (entrevistada, 2019), que está presente no Movimento desde o início, em 2004, os trabalhadores passaram apenas dois dias na primeira ocupação. Após saírem da fazenda Santa Maria, foram para o Instituto Nacional de Colonização e Reforma Agrária (Incra), mas não conseguiram o que objetivavam. Então, voltaram e ficaram à "beira da estrada" por um ano; logo depois, ocuparam a fazenda Divino Garcia. Depois de passarem um período nessa fazenda, voltaram para o Incra. Durante esse período, passaram por muitas dificuldades e sofrimentos, até que o Incra fez o assentamento das famílias no local onde se encontram atualmente.

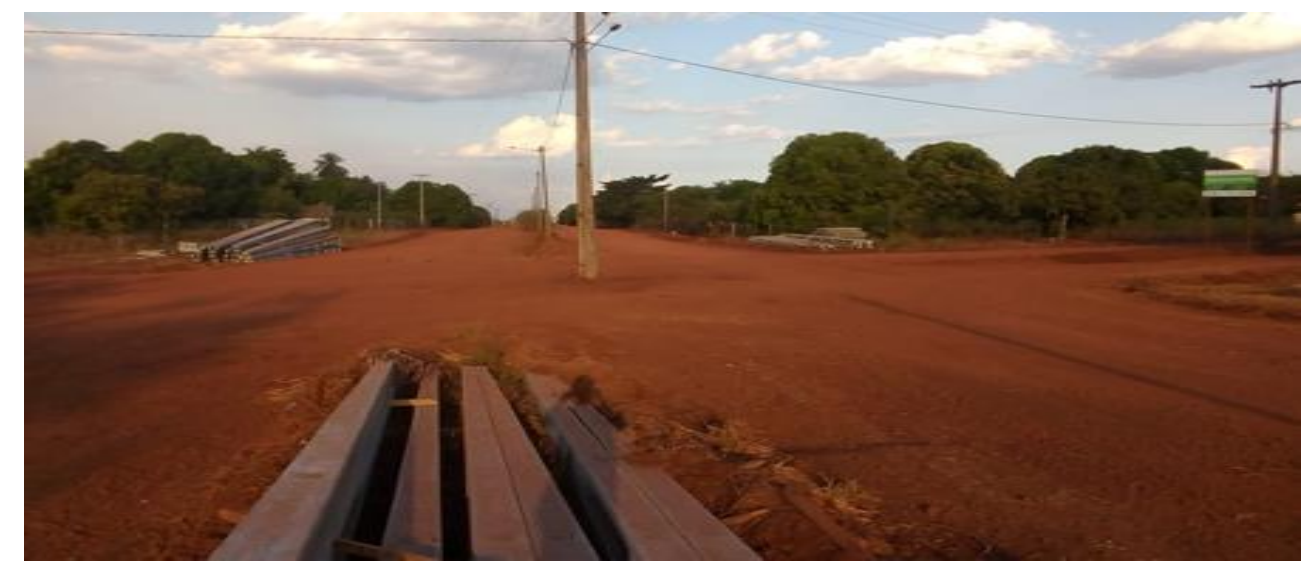

Figura 2: Centro do Assentamento Oziel Alves.

Fonte: José Paulo Ramalho de Araújo (2019).

O assentamento, apesar de ser pequeno para os moradores, já possui sua estrutura com casas, roças, unidade escolar, igrejas e comércios, pois os habitantes que lá se fixaram já são famílias assentadas. Mas, de acordo com os relatos, ao chegarem ao local enfrentaram vários problemas e dificuldades para a obtenção de um bom resultado. Suas moradias, construídas com tábuas ou palha, eram pouco seguranças; além disso, não existiam transportes que 
pudessem levar os moradores à cidade ou os alunos à escola. Atualmente, o assentamento conta com transportes e casas mais resistentes.

É importante compreender que, logo após um acampamento se tornar assentamento, a luta passa a ser pela permanência das famílias na terra. No início do seu surgimento, a estrada era extremamente ruim, estreita, com tocos e buracos; até mesmo para o Samu era difícil realizar o seu serviço. Era complicado adentrar ao local que, hoje, já possibilita a passagem de carros pequenos, motos e caminhões (Figura 3 ).

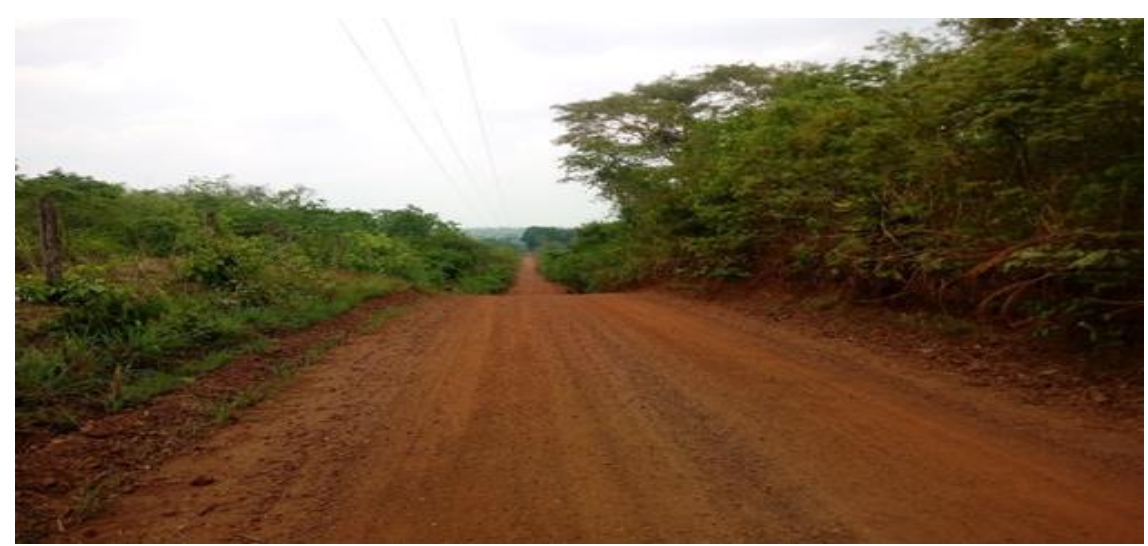

Figura 3: Estrada para o Assentamento Oziel.

Fonte: Alessandra da Conceição Morais (2019).

Ainda existem sérios desafios a serem vencidos, como a organização do assentamento, a implantação de uma infraestrutura para uma escola de qualidade (com demanda de Ensino Fundamental II e Ensino Médio), estradas asfaltadas, transportes escolares etc.

De acordo com a pesquisa realizada, nas conquistas já alcançadas, as mulheres camponesas sempre estiveram presentes, ocupando diversos espaços para garantir a estrutura de um assentamento melhor, ou seja, uma estabilidade social e econômica para os seus moradores. A seguir, são apresentadas fotos (Figuras $4 \mathrm{~A}-\mathrm{F}$ ) atuais do assentamento, resultado das conquistas da luta pela terra. 


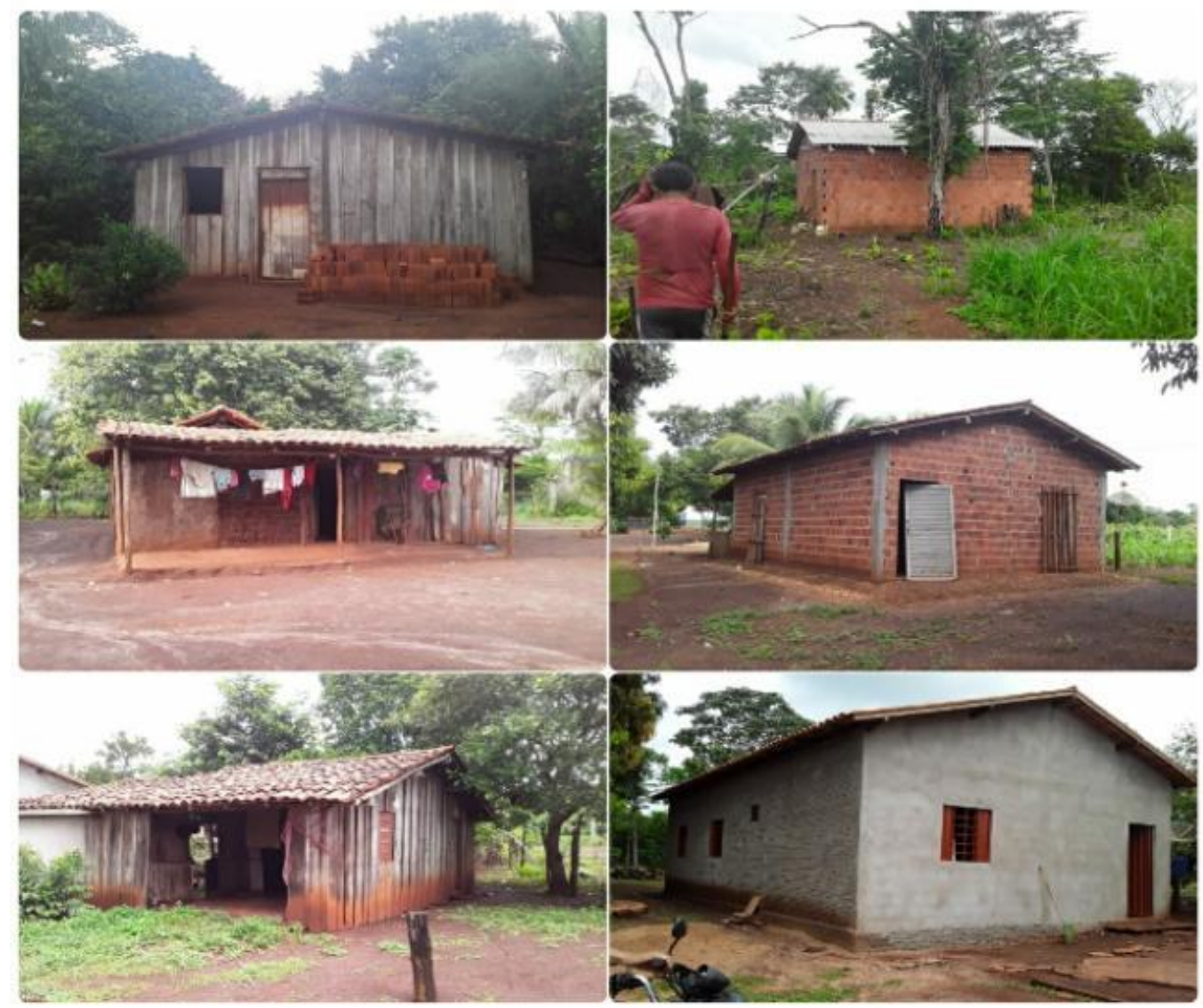

Figura 4: A-F - Casas das/os moradoras/es no Assentamento Oziel Alves. Fonte: Alessandra da Conceição Moraes, 2019.

\section{A luta pela terra e a participação das mulheres camponesas}

Ao observarmos o contexto histórico do MST (ALMEIDA, 2017), percebemos que, apesar da invisibilidade pela história, as mulheres sempre tiveram um papel de protagonismo nas lutas travadas pelos trabalhadores rurais. Nos relatos de algumas camponesas do Assentamento Oziel, também se percebe que essas mulheres viveram (no período de acampamento) e ainda vivem (enquanto assentadas) problemas que surgem no decorrer da luta para obtenção da terra e por sua manutenção. Ainda hoje, essas mesmas mulheres camponesas se fazem presentes, buscando uma estrutura melhor para o assentamento, seguindo na luta após a terra conquistada e combatendo os problemas que surgem no dia a dia.

Como define Raffestin (1993), o território é uma produção a partir do espaço e revela relações marcadas pelo poder, que é exercido por pessoas ou grupos e está intrínseco em todas as relações sociais. Nos espaços de trabalho, as mulheres camponesas estabelecem uma relação entre os serviços da casa e da roça, atuando nessas duas esferas - sobretudo na luta política - e organizando e mobilizando as companheiras para juntas, conquistarem o território. Raffestin (1993, p. 53-58) trata dessa questão destacando que o território é "[...] o lugar de todas as relações $[\ldots]$ ", a partir do que, afirma o autor, o poder político é intercambiado entre diferentes dimensões da vida social. 
É graças à luta das mulheres que as questões de gênero foram incorporadas às perspectivas de luta do MST e que se compreendeu a sua indissociabilidade da luta pela terra. É com o amadurecimento da luta desenvolvida por essas mulheres que cresce, no campo, uma atuação que reflete sua identidade camponesa e popular.

De acordo com Almeida:

A luta das mulheres camponesas é notadamente por direitos e por uma vida digna no campo, é, sobretudo, uma luta por espaços democráticos de participação e organização das trabalhadoras do campo, como um movimento classista, porque elas compõem a classe trabalhadora e buscam relações de igualdades em uma sociedade tão desigual [...]. (ALMEIDA, 2017, p. 197).

A mulher desempenha um papel fundamental no MST; no entanto, o reconhecimento de sua importância passa por transformações e difere do que estabelecem os objetivos fundamentais do Movimento, que são pautados na igualdade de gênero.

Fernandes (2000) destaca que as lutas camponesas sempre estiveram presentes no contexto histórico do Brasil. Percebe-se que, em um país invadido, escravizado, colonizado para a exploração e o enriquecimento da sua metrópole até as últimas consequências, a luta pela terra sempre existiu nos seus mais de 521 anos de história. Segundo o autor:

Há 500 anos, desde a chegada do colonizador português, começaram as lutas contra o cativeiro, contra a exploração e consequentemente contra o cativeiro da terra, contra a expulsão, que marcam as lutas dos trabalhadores. Das lutas dos povos indígenas, dos escravos e dos trabalhadores livres e, desde o final do século passado, dos imigrantes, desenvolveram-se as lutas camponesas pela terra. Lutas e guerras sem fim contra a expropriação produzida continuamente no desenvolvimento do capitalismo (FERNANDES, 2000, p. 1).

No final da década de 1970 e durante década de 1980, as lutas pelo restabelecimento da democracia, "[...] da liberdade de expressão e de direitos políticos e sociais [...]" (ESMERALDO, 2013, p. 241) confluem as manifestações organizadas por diversos segmentos da sociedade. Encontram-se, nessa luta, operários, trabalhadores rurais, setores progressistas da Igreja Católica, partidos de esquerda, movimentos estudantis, profissionais liberais e professores da academia. As "ações políticas e públicas" desses sujeitos fundamentaram o plano sócio-histórico para o surgimento da Comissão Pastoral da Terra (CPT), do Partido dos Trabalhadores (PT), da Central Única dos Trabalhadores (CUT) e do MST. Mas, nem sempre os livros didáticos esclarecem que as mulheres integram esses espaços como trabalhadoras em busca da efetivação de direitos para a classe como um todo ou que lutam por questões que Ihes dizem respeito enquanto sujeitas nessa construção social. Nesse sentido: 
patriarcais, estruturas objetivadas, inscritas e instituídas nos corpos, objetos, tempos, espaços e nos trabalhos de homens e de mulheres, levam as mulheres a buscar articular-se em movimentos sociais e políticos para construir sua afirmação como trabalhadoras rurais (ESMERALDO, 2013, p. 241).

A partir da afirmativa da autora, observa-se uma dimensão tratada neste trabalho: o sentido coletivo da luta que está pautada pelo Movimento, as dificuldades e impossibilidades da transformação individual da condição de vida das mulheres que, portanto, passam a integrar as lutas coletivas dos trabalhadores.

A significativa participação feminina no I Encontro Nacional dos Trabalhadores Sem-Terra, realizado em janeiro de 1984, na cidade de Cascavel, Paraná, foi fruto do processo que se desencadeou a partir dos marcos de participação das mulheres citados anteriormente. O processo de crescimento da sua atuação na luta pela terra, no Brasil, possibilitou as dimensões da força e do potencial de sua formação e organização política, proporcionando a base necessária para a sua mobilização e significativa participação nesse encontro que marca a luta do campo.

A luta das mulheres desencadeada na década de 1980 pelo reconhecimento de sua profissão como trabalhadora rural é permeada pelo signo da contradição. Ao mesmo tempo em que seu trabalho é considerado como "ajuda" no interior das relações familiares para que se possa cumprir e manter a ordem moral e de autoridade entre o casal, o trabalho feminino é afirmado e positivado publicamente para fomentar as lutas pelo seu reconhecimento profissional (ESMERALDO, 2013, p. 241).

Todos esses são exemplos de como as mulheres lutaram e estão lutando para ultrapassar o lugar de subalternidade que Ihes foi socialmente construído, integrando-se às lutas sociais mais importantes da história do País. São exemplos de como a luta pela terra, no Brasil, é marcada pela participação das mulheres. Dessa maneira, essas camponesas do assentamento Oziel se encontram na linha de frente, combatendo os conflitos gerados pelas questões agrárias.

As mulheres que estiveram presentes na luta pela conquista do assentamento trouxeram, nas suas falas, os desafios que enfrentaram no período de luta pela terra. Quando estavam à beira da estrada, nas ocupações das fazendas, o medo e as dificuldades eram bem maiores.

São tantas que não sei nem como te contar (pausa), a primeira é que eu era sozinha, enfrentamos policiais fazendeiros, no Divino Garcias a polícia ia todo dia, teve uma vez que estávamos do lado de um brejo, acredita que a polícia passou uns dois dias do outro lado esperando um movimento nosso (risos), passávamos noites sem dormir, ficava com a luz apagada por causa dos pistoleiros (Entrevistada FRANCISCA SILVA, 2020).

Em contraposição a essa violação de direitos sociais, as trabalhadoras rurais criam e recriam seu modo de resistir e de lutar por seus direitos, elaborando estratégias que vão desde a ocupação de terras da União griladas 
por fazendeiros e de instituições que são responsáveis pelas políticas agrárias (por meses ou anos), até a permanência à beira da estrada, em barracos cobertos por palha de coco babaçu. Sobre os acampamentos, Luzia destaca que "[...] passaram apenas dois dias em uma fazenda e logo tiveram que sair do local." (entrevistada LUZIA, 2019).

Como destacado anteriormente, a construção de um território se dá a partir da ação de grupos sociais. Essa ação pode ter o objetivo de apropriação, produção ou dominação do espaço geográfico. Com a territorialização, esses grupos estabelecem suas territorialidades, que são as atividades cotidianas que passam a ser desempenhadas no território (SAQUET, 2007; HAESBAERT, 2006). Podemos afirmar que a ação das mulheres foi importante para o Movimento desde o final da década de 1970, pois, nessa época, a luta pela terra deixava de ter um caráter apenas masculino e passava a envolver contingentes de famílias inteiras. Os integrantes do MST recebem como orientação a igualdade entre os gêneros, visando ao reconhecimento das mulheres nas áreas de produção, educação e economia. Contudo, a maioria das lideranças do Movimento ainda é formada por homens, estando o gênero associado à ideia de força.

Em seu livro Subjetividade e gênero no MST, Melo (2010) relata que uma das resoluções discutidas e aprovadas no I Encontro Nacional dos Assentados pelo MST diz respeito ao posicionamento da mulher assentada. Essa resolução mostrava que a preocupação com as relações de poder e as questões de gênero estavam começando a ganhar força nas pautas dos problemas a serem resolvidos. Ainda no mesmo livro, Melo (2010) aponta que:

Já em 1986, depois de dois anos após sua fundação oficial, as mulheres trabalhadoras rurais assentadas pelo MST, denunciam falhas na busca de superação de antigos preconceitos que impedem a conquista de ralações igualitárias mesmo nas áreas influenciadas pelo movimento (MELO, 2010, p. 120).

Mesmo com alguns problemas resolvidos, ainda existem preconceitos em relação à igualdade nas relações de gênero. A importância da mulher na luta pela terra está no trabalho cotidiano por ela realizado, que vai desde a labuta na terra (no caso dos assentamentos) e o trabalho de casa, até a militância política. Pode-se observar, nas falas de algumas mulheres, que, depois da terra conquistada, além de cuidarem da casa e do serviço doméstico, também trabalham na roça junto com seus companheiros para garantir o sustento da família (Figuras 10A-D). O espaço doméstico é, praticamente, todo feminino; ou seja, as mulheres afirmam que há uma pequena participação masculina nas tarefas de casa que, a princípio, são consideradas responsabilidade da mulher. 

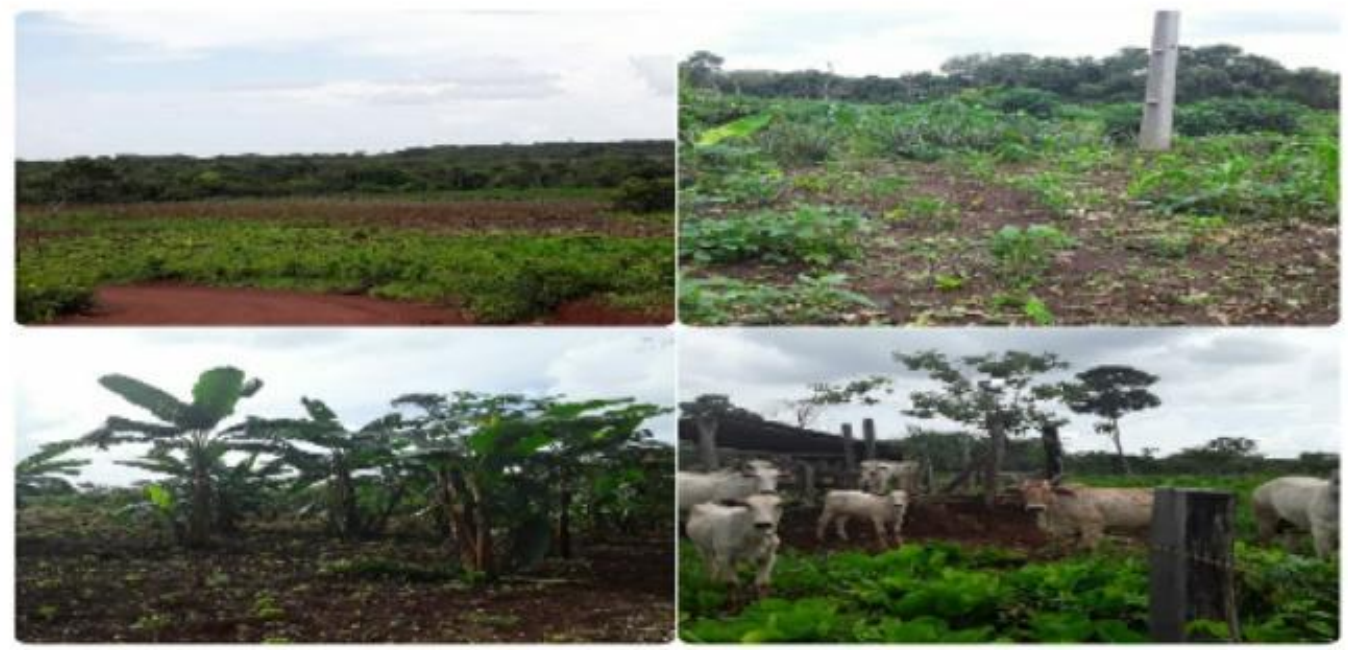

Figura 5: Hortas, animais e roças no Assentamento Oziel Alves.

Fonte: Alessandra da Conceição Moraes (2019).

A entrevistada Genilda relata que, em relação às suas trajetórias de lutas, as mulheres sofreram para chegar aonde estão, e que foram muitas as dificuldades enfrentadas para que pudessem possuir a terra:

Enfrentamos muitas dificuldades, são tantas! Enfrentei polícia, fazendeiros, corríamos com medo da polícia, outra hora era a polícia que corria com medo de nós [...] (risos)! Fazia barracos e ao mesmo tempo tinha que desmanchar para mudar, era uma correia, mal dormia, fazia barraco e mudava barraco (Entrevistada: GENILDA COSTA, 2020).

$\mathrm{Na}$ fala da interlocutora, observamos seu medo e sua tristeza ao revisitar o passado, ainda que ela mostre um sorriso quando destaca que os policiais também tinham medo de enfrentá-los. Entretanto, Genilda abaixa a cabeça quando fala sobre as várias ocasiões em que não conseguiu dormir à noite, demostrando a insegurança e o perigo que passaram naquele tempo. Mas, ao lembrar, destaca que está bem melhor do que antes:

Tive que deixar meu marido doente, meus filhos e viajei para o movimento, para conseguir a terra. Ganhava apenas Trinta reais ( $R \$ 30,00)$ do bolsa família e com esse dinheiro comprava alguns remédios para meu esposo, comida para os filhos e o que sobrava pagava a viagem de volta. E muitas vezes nem sobrava e eu tinha que pegar carona para poder ir, mas hoje me alegro, pois tenho a minha terra (Entrevistada NILZA, 2020).

No momento em que nos contava sobre os desafios da luta pela terra, Nilza dá uma pausa, respira, e continua a falar sobre como era difícil seguir lutando, tendo que deixar o companheiro doente, sem poder parar.

É por meio das experiências de lutas que as mulheres desse e de outros assentamentos - movidas pela participação política na luta pela terra constroem repertórios de sua força e reafirmam suas identidades. Essas mulheres não são as mesmas de antes do acampamento, mas, constituem-se por meio de um processo de formação cultural (Hall, 2009) em que ocorrem 
transformações e mudanças e se constrói, a partir de seu protagonismo político, um novo olhar sobre a sociedade.

\section{Considerações finais: trajetórias de uma caminhada}

Procuramos compreender as diversas atuações das mulheres no interior do assentamento Oziel Alves, refletindo e analisando os diversos papéis desempenhados por elas na organização da luta pela terra e no processo de territorialização do assentamento das famílias.

Estudar o movimento das mulheres assentadas é buscar, sobretudo, compreender suas relações na participação política na luta pelo assentamento das famílias que buscam melhores condições de vida, tanto as que vivem na periferia das cidades (que saíram do campo por não ter como viver) como as que continuam no campo. Nesse processo de migração, as famílias buscam, constantemente, outros lugares para reconstruírem suas vidas.

Com o objetivo de compreender as atuações das mulheres camponesas, em diferentes espaços públicos e privados, procuramos destacar o processo de lutas e suas participações e organizações nos acampamentos e, principalmente, no assentamento. Percebemos que os assentamentos, enquanto territórios criados, hoje representam outro componente no processo de produção e organização do espaço agrário brasileiro. Enquanto território, esse espaço adquire outra forma de organização territorial, uma nova paisagem, pois essas relações estarão presentes na construção do território e nas territorialidades elaboradas.

Saquet (2007) ressalta que o território significa natureza e sociedade; economia, política e cultura; ideia e matéria; identidades e representações; apropriação, dominação e controle; descontinuidade, conexão e rede; degradação e proteção ambiental; terra, formas espaciais e relações de poder; diversidade e unidade. É um produto histórico, uma condição de processos sociais. A partir das análises apresentadas em todo o texto, podemos afirmar que, na luta para conquistar a terra, as mulheres camponesas apresentam diferentes estratégias de atuação, como princípios ideológicos e políticos. Porém, com um aspecto em comum: são lutas que se desenvolveram devido à expansão capitalista sobre o campo brasileiro.

Enquanto as relações sociais são desenvolvidas, os indivíduos desempenham papéis sociais determinados por processos sociais; normas definidas pelas instituições e organizações sociais que apresentam suas dinâmicas de acordo com a cultura e o tempo. Contudo, há uma clara distinção entre as identidades e os papéis sociais.

A partir desta pesquisa, que tem sua continuidade no mestrado desde 2020, afirmamos que os desafios enfrentados pelas mulheres assentadas estão em curso, pois percebemos que os diálogos apresentados não se esgotaram.

Mulheres camponesas cujas trajetórias construíram sonhos para embalar as transformações sociais; mulheres trabalhadoras que encontraram, na sua participação nos movimentos sociais, nas Igrejas, nos partidos e nos sindicatos, sentidos, motivos e condições para a reconstrução de suas vidas. Vidas cujas bases construíram territorialidades. 


\section{REFERÊNCIAS}

ALMEIDA, Rejane Cleide Medeiros de. Práxis política do movimento dos trabalhadores rurais sem-terra (MST)- TO: trajetória de organização e formação política. 2017. 231 f. Tese (Doutorado em Sociologia) - Universidade Federal de Goiás, Goiânia, 2017.

ESMERALDO, Gema, Galgani Silveira Leite. O protagonismo político de mulheres rurais por seu reconhecimento econômico e social. In: Delma Pessanha Neves, Leonilde Servolo de Medeiros (Org.). Mulheres camponesas: trabalho produtivo e engajamentos políticos. Niterói: Alternativa, 2013, p. 237-256.

FERNANDES, Bernardo Mançano. A formação do MST no Brasil. São Paulo: Vozes, 2000.

GEERTZ, James Clifford. A interpretação das Culturas. 1a. Ed. 13a reimpr. Rio de Janeiro: Livros Técnicos e Científicos. 2008.

HAESBAERT, Rogério. Territórios alternativos. 2a. Ed. São Paulo: Contexto, 2006.

HALL, Stuart. Cultura e Representação. Rio de Janeiro: PUC-Rio: Apicuri, 2016.

HALL, Stuart. Da diáspora: identidade e mediações culturais. Belo Horizonte: Editora da UFMG, 2009.

SCOTT, Joan. Gênero: uma categoria útil de análises históricas. Gênero e a política da história. New York, Columbia University Press. 1989.

Mapa Assentamento Oziel Alves. Disponível em <https://www.google.com/maps/place/Porto+Franco,+MA,+65970-000/@6.3479228.a >. Acesso em: 20 out. 2020.

MELO, Denise Mesquita de. Subjetividade e gênero no MST: observações sobre documentos publicados entre 1979 e 2000. In: GOHN, Maria da Glória (Org.). Movimentos sociais no início do século XXI. Cap. 5, p. 113-143. Petrópolis: Vozes, 2010.

MOVIMENTO DOS TRABALHADORES RURAIS SEM TERRA. O desenvolvimento do MST: Disponível em: https://brasilescola.uol.com.br/sociologia/mst.htm. Acesso em: 20 jun. 2021.

RAFFESTIN, Claude. Por uma geografia do poder. São Paulo: Ática: 1993. 
SAQUET, Marco Aurélio. Abordagens e concepções de território. São Paulo: Expressão Popular, 2007.

SAQUET, Marco Aurélio. Por uma abordagem territorial. In: SAQUET, Marcos Aurélio; SPOSITO, Eliseu Savério. Territórios e territorialidades: teorias, processos e conflitos. São Paulo: Expressão Popular, 2009, p. 73-94.

TUAN, Yi-Fu. Espaço e Lugar. A perspectiva da experiência. São Paulo: DIFEL, 1983.

Recebido em: 30 de junho de 2021. Aceito em: 15 de setembro de 2021. Publicado em: 15 de dezembro de 2021. 